\title{
ESCOLA SEM PARTIDO E O ENSINO DE GEOGRAFIA: UMA AMEAÇA A CRITICIDADE DENTRO DE SALA DE AULA
}

\author{
José Gustavo Santos da Silva ${ }^{1}$ \\ Rafaela Brito Pereira ${ }^{2}$ \\ Mario Ricardo Guadagnin ${ }^{3}$
}

\section{Resumo}

O movimento "escola sem partido" tem ganhado força nos últimos anos no cenário político brasileiro, motivados pela crise estrutural que o sistema capitalista tem enfrentado, e pelas ascensões de grupos conservadores no poder legislativo/executivo. O objetivo deste trabalho é demostrar teoricamente como esta lei está estruturada e como influenciará no trabalho docente em geral e no caso do professor de geografia, tento como base as teorias da nova geografia ou geografia crítica para formular uma crítica a este movimento, partindo da aprovação PL № 130/2017 que estabelece o "programa escola sem partido" do município de Criciúma/SC no ano de 2017, e como este afetará a cátedra dos professores do município.

\section{Palavras-chave}

Escola sem partido; Ensino de geografia; Criticidade.

\section{Resumen}

El movimiento "escuela sin partido" ha ganado fuerza en los últimos años en el escenario político brasileño, motivados por la crisis estructural que el sistema capitalista he enfrentado, y por las ascensiones de grupos conservadores en el poder legislativo / ejecutivo. El objetivo de este trabajo es demostrar teóricamente con esta ley está estructurada y como influyó en el trabajo docente en general y en el caso del profesor de geografía, intento como base las teorías de la nueva geografía o geografía crítica para formular una crítica a este movimiento, partiendo de la aprobación PL № 130/2017 que establece el "programa escuela sin partido" del municipio de Criciúma / SC en el año 2017, y cómo éste afectó a la cátedra de los profesores del municipio.

\section{Palabras clave}

Escuela sin partido, Enseñanza de geografía; criticidad

\footnotetext{
${ }^{1}$ Graduado em Geografia - Universidade do Extremo Sul Catarinense - UNESC. Mestrando em Ciências Ambientais - PPGCA/UNESC - E-mail: gustasantos92@gmail.com

${ }^{2}$ Graduada em Geografia - Universidade do Extremo Sul Catarinense - UNESC; rafaelabritop@ gmail.com

${ }^{3}$ Professor do Curso de Geografia da Universidade do Extremo Sul Catarinense - UNESC. Mestre em Geografia - UFSC. Doutorando em Ciências Ambientais - UNESC.
} 
Seria na verdade uma atitude ingênua esperar que as classes dominantes desenvolvessem uma forma de educação que proporcionasse às classes dominadas perceber as injustiças sociais de maneira crítica (FREIRE, 1984, p. 89).

\section{INTRODUÇÃO}

A crise política e econômica do atual sistema tem levado durante décadas um negligente investimento na área da educação em países subdesenvolvidos, estes são influenciados pelo imperialismo de países capitalistas. Conservar um sistema desigual, classista e explorador é papel fundamental do atual sistema econômico, que se baseou nestes princípios desde seu alicerce para tornar-se hegemônico no planeta.

Este sistema usa de meios para se conservar, e através do estado reproduz suas ideias. A escola é um meio eficiente para disseminar as ideologias dominantes e reproduzir o sistema (SAVIANI, 2012). O sistema dominante prega em países subdesenvolvidos para a grande parcela da população um ensino repetitivo e mnemônico, sem a interação de aluno/professor e sem a troca de saberes, "ou, por outras palavras, os professores e os alunos são treinados a não pensar sobre o que é ensinado e sim, a repetir pura e simplesmente o que é ensinado" (OLIVEIRA, 1991 p. 28).

O objetivo maior é formar cidadãos para o mundo e fazer destes mão de obra para o sistema e torná-los ao mesmo tempo em que produzem os bens materiais da sociedade, consumidores ativos (BAUMAM, 2001). Vesentine (1991

p. 31) afirma que "a escola contribui para a reprodução do capital: habitua os alunos a disciplina necessária ao trabalho na indústria moderna, a realizar sempre tarefas novas sem discutir para que"

A educação brasileira segue a mesma lógica a muitas décadas, acentuando-se no período da ditadura civil militar (1964-1985), 21 anos de conservadorismo acentuado, de repressão e cerceamento do direito de expressão, Rocha et al (2009 p. 3) aponta que "Neste período, a educação visava à formação de indivíduos adequados à nova ordem social" que era imposta pelo regime. 
Após 1988 com a "redemocratização" do país com a promulgação da constituição cidadã, tomaram o poder grupos conservadores, principalmente fundamentalista religiosos e aqueles que tinham apreço ao antigo regime. Mesmo após 2002 com a ascensão do Partido dos Trabalhadores ao poder, as bancadas fundamentalistas religiosas, armamentistas e ruralistas (BBB/Boi, Bala e Bíblia) como ficaram conhecidas não deixarem de impor suas ideias conservadoras que buscam legitimar um sistema de desigualdade e exploração dos mais pobres.

Após a "redemocratização" do país, o papel da escola deveria ter mudado, mas ainda acaba sendo a de reproduzir a ideologia dominante, apesar de ao longo dos anos de governo PT as áreas sociais como educação e habitação tiveram uma pequena ascensão, nada que se trabalhe para mudar 0 sistema e erradicar a desigualdade social.

O PT ficou no poder até meados de 2016, (31 de agosto de 2016) quando a então presidente Dilma Roussef foi impedida de exercer seu mandato. Pode-se dizer que uma nova era conservadora inicia-se de forma acentuada, pelo tomada do poder por grupos de direita (PMDB, PSDB, PSC, DEM, entre outros). Estes grupos, tomam voz ativa na sociedade e seus seguidores até então "escondidos" vieram à tona novamente pregando suas ideologias até então "esquecidas". Miguel (2016) analisa que já a partir dos anos 2010 houve no Brasil um avanço das vozes abertamente conservadoras no debate público em todas as áreas, seja na saúde, nos transportes, na segurança dentre outras.

$\mathrm{Na}$ área da educação temos como exemplo desta nova era de conservadorismo, a apresentação do Projeto de Lei 867/2015, mais conhecido como "Escola sem Partido". "Em defesa deste projeto se destacam alguns segmentos da sociedade, representados predominantemente por políticos conservadores, liberais econômicos, ou conservadores moralmente e parte significativa da sociedade civil" (ALENCAR, 2017 p. 127). Este PL (867/2015) que está tramitando em âmbito nacional na Câmara dos Deputados ganha com o tempo alguns filiados e simpatizantes, estes encabeçados por políticos de diversas cidades, espalham as ideias do escola sem partido e tentam aprová-lo (alguns com sucesso) em seus municípios, nos planos de educação. 
Sendo a geografia uma disciplina que trata diretamente de questões sociais e políticas na sua área humana, ver-se-ia como um dos alvos do PL e de seus defensores. Pode dizer que esse texto se trata de um ensaio analítico das possíveis repercussões desse projeto que se coloca num cenário antidemocrático, tido como "Lei da mordaça", partindo de uma pesquisa documental e bibliográfica discute-se sua aprovação no município de Criciúma/SC, sua inconstitucionalidade e sua ameaça a uma educação crítica/democrática.

$\mathrm{Na}$ primeira seção apresenta-se 0 projeto de Lei, sua gênese e desdobramentos políticos e educacionais. Na segunda seção sua aprovação na Câmara Municipal de Criciúma/SC e posteriormente a ameaça ao ensino crítico da geografia e seu cerceamento as discussões em sala de aula nas escolas municipais.

\section{A GÊNESE DO PROJETO SEUS FILIADOS}

$\mathrm{O}$ ante projeto nasce em meados de 2004, proposto pelo advogado Miguel Nagbi, até então sem força direta na comunidade e no meio político. $O$ ante projeto de lei toma força a partir de 2015, quando começa a tramitar na Câmara de Deputados como PL 867/2015 intitulado "Programa Escola sem Partido" que dispõe sobre a inclusão do programa na Lei № 9.394, de 20 de dezembro de 1996 (Diretrizes de Bases da Educação Nacional).

Vários projetos espelhados na proposta de lei, tramitaram em outras assembleias legislativas em âmbito municipal, estadual e e sua maior expressão no Congresso Nacional. Em âmbito federal proposto em primeira parte pelo deputado federal Izalci Lucas (PSDB/DF). Desde 2014, mais de 62 projetos de lei (PLs) relacionados ao movimento Escola sem Partido tramitaram ou tramitam em casas legislativas de pelo menos 12 estados e 23 cidades do Brasil.

Os dados são do Movimento de Olho nos Planos ${ }^{4}$ de agosto de 2017, já no mês seguinte no município de Criciúma/SC seria sancionado o PL 130/2017 que espelhado no projeto nacional institui entre as diretrizes de bases da

${ }^{4}$ Os dados podem ser consultados no site do movimento: http://www.deolhonosplanos.org.br/projetos-leiescola-sem-partido/ 
educação do município o projeto "escola sem partido", de autoria do vereador Daniel Freitas (PP), este foi aprovado em 11 de dezembro de 2017 abaixo de protestos contrários ao movimento.

Alguns dos PLs espelhados no projeto original sofreram algumas alterações nas suas disposições preliminares, mas nada que extingue-se 0 objetivo original do projeto, o de cercear a discussão e exigir do professor "neutralidade" em sala de aula.

Em alguns munícipios em que estes PLs espelhados no anteprojeto de lei, estavam tramitando, acabaram sendo aprovados. O mais repercutido foi 0 do estado de Alagoas - Lei 7800/2016 instituía o programa "Escola Livre", em primeiro momento aprovado, mas julgado inconstitucional em uma decisão liminar concedida pelo ministro Luís Roberto Barroso do STF (Supremo Tribunal Federal), em 22 de março de 2017.

O exemplo mais próximo a Criciúma, é a aprovação da emenda ao Plano Municipal de Educação (Lei 4268/2017) de Tubarão que espelhados no projeto "escola sem partido", cerceiam as discussões sobre de gênero dentro das escolas.

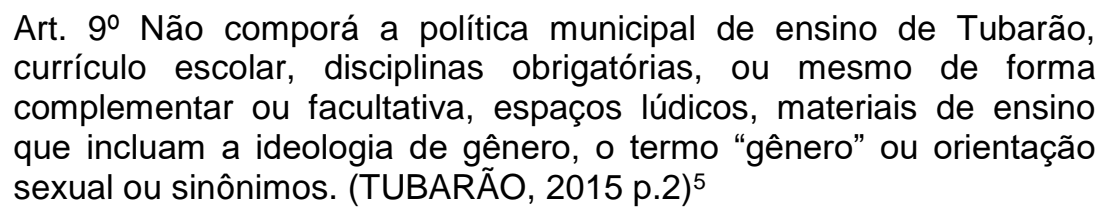

Ainda na mesma câmara legislativa tramita o PL 23/2017 que traz toda a essência do projeto "Escola Sem Partido" para dentro da rede municipal de ensino. Proposto pelo vereador Lucas de Souza Esmeraldino (PSDB) e Carlos Alexandre das Neves (PSDB), já foram realizadas audiências públicas com presença do autor do projeto em âmbito nacional Miguel Nagbi e contraponto a presença do professor Fernando de Araújo Pena/UFF líder do movimento Escola Democrática.

Uma das justificativas apresentadas pelos vereadores (uma cópia do PL original) está na transcrição abaixo.

\footnotetext{
${ }^{5}$ TUBARÃO. lei $\mathbf{n}^{\mathbf{0}} \mathbf{4 2 6 8}$, de 24 de julho de 2015. Aprova o plano municipal de educação de tubarão e dá outras providências. Disponível em > https://leismunicipais.com.br/a1/plano-municipal-de-educacao-tubaraosc.
} 


\section{CRIARR EDUCAÇ̃̃o}

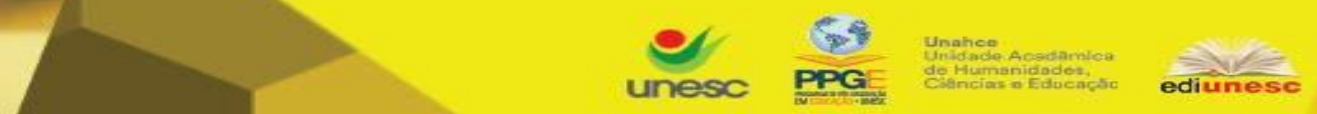

É fato notório que professores e autores de livros didáticos vêm-se utilizando de aulas e de suas obras para tentar obter a adesão dos estudantes a determinadas correntes políticas e ideológicas; e para fazer com que eles adotem padrões de julgamento e de conduta moral - especialmente moral sexual -incompatíveis com os que lhes são ensinados por seus pais ou responsáveis. Diante dessa realidade, conhecida por experiência direta de todos os que passaram pelo sistema de ensino nos últimos 20 ou 30 anos -, entendemos que é necessário e urgente adotar medidas eficazes para prevenir a prática da doutrinação política e ideológica nas escolas, e a usurpação do direito dos pais a que seus filhos recebam a educação moral que esteja de acordo com suas próprias convicções. (TUBARÂO, 2017)

A questão aqui levantada a partir da justificativa dos autores que pregam uma escola "sem partido", onde na parte grifada afirmam que essa doutrinação político partidária está presente no sistema de ensino nos últimos 20 ou 30 anos. Se subtrairmos do nosso ano atual (2018) os autores afirmam que desde 1988 a doutrinação político partidária (de "esquerda") está dentro do sistema de ensino. A questão aqui levantada seria: E antes de 1988? Não havia doutrinação nas escolas?

Talvez a dita doutrinação de "esquerda" como pregam políticos e ativistas de extrema direita não, havia-se uma rejeição aos regimes socialistas aos seus aliados e ao pensamento de esquerda mundial. Na citação abaixo é apresentado um trecho de um discurso do deputado federal Jair Bolsonaro durante uma sessão da câmara de deputados.

Sr. Presidente, para encerrar, quero cumprimentar V.Exa., autor do Projeto Escola sem Partido, que estamos debatendo na Comissão de Educação da Câmara dos Deputados. Agora, enquanto debatemos esse tema, os livros do MEC - e tenho aqui vários livros - já impõem essa ideologia de esquerda nas escolas, entubam as crianças, pregam que o socialismo é uma maravilha. E mais: agora perderam a noção do ridículo. Espero que o Ministro da Educação, Mendonça Filho, coloque a bom termo isso. (Discurso do deputado Jair Bolsonaro, 2016)

O deputado caracterizado como de extrema direita, acusa os livros didáticos do Ministério da Educação (MEC) a "entubarem" a ideologia de esquerda nas crianças, desconsiderado a capacidade intelectual dos alunos, considera-os uma tabula rasa, uma folha em branco, como trata o criador do projeto, este ser sem nenhum tipo de convicção e opinião, o projeto caracteriza

\footnotetext{
${ }^{6}$ Discurso durante a sessão 130.2.55.O, Hora: 19h52, Data: 31/05/2016, transcrita e disponível no link > http://www.camara.leg.br/internet/sitaqweb/TextoHTML.
} 
a sala de aula como o lugar de "audiência cativa", onde os alunos ficam a mandos do professor "doutrinador, do militante de esquerda".

O MESP prega o que a muitos anos Paulo Freire caracterizava e criticava como "educação bancaria" onde o professor seria apenas um narrador, e o aluno um ouvinte. Prega a neutralidade de conteúdo, onde o professor passara apenas aquilo que lhe foi instituído, sem demostrar opinião, transforma o professor em um mero repassador de informação, mero narrador de histórias, sem problematizar as mesmas. (FREIRE, 1994)

\begin{abstract}
A narração, de que o educador é o sujeito, conduz os educandos à memorização mecânica do conteúdo narrado. Mais ainda, a narração os transforma em "vasilhas", em recipientes a serem "enchidos" pelo educador. Quanto mais vá "enchendo" os recipientes com seus "depósitos", tanto melhor educador será. Quanto mais se deixem docilmente "encher", tanto melhores educandos serão. (FREIRE, 1994 p.34)
\end{abstract}

Uma escola onde a reprodução do conhecimento toma forma, onde 0 professor fala e os alunos escutam sem contrapor, onde a educação bancária é a pioneira, não pode ser de forma alguma uma educação emancipatória ou libertária de pensamentos. Bell Hooks (2013, p. 25) dissemina essa ideia de educação como prática de liberdade, para ela a "educação como prática de liberdade é um jeito de ensinar em que qualquer um pode aprender", o MESP desconsidera as especificidades de cada aluno em sala de aula, desconsidera a situação precária da maioria das escolas no país, desconsidera uma sala com 30 ou mais alunos. A educação pública em si deveria ser uma forma de emancipação social, e por meio dos professores essa deveria ser feita, mas não é, sendo assim a escola ainda nos dias atuais "reproduz a dominação e a exploração" (SAVIANI, 2012, p. 29).

A escola na sua estrutura não se modificou ao passar dos anos e nem se adaptou as novas realidades, na sua estrutura histórica e atual torna-se apenas um legitimador da situação social.

Desta forma a escola cumpri um papel importante na dominação ideológica, apresenta-se como um dos muitos aparelhos ideológicos do estado (AIE), os quais são listados na obra de Althusser (1987). Estes aparelhos ideológicos do Estado apresentam-se de forma a dominar ideologicamente as massas, e secundariamente se por algum motivo a ideologia não cumprir seu 
papel (quase raramente não cumpre) a repressão entra em campo e faz o seu trabalho, estes representados pela polícia e pelo exército. (SAVIANI, 2012)

A ideologia ou os AIE's na obra de Althusser (1987), se apresentam de forma materializada dentro da sociedade capitalista, reproduzindo as ideias dominantes, onde dominados não se reconhecem como dominados, e (re) produzem as ideias dominantes. O AIE escolar cumpre o seu papel na sociedade dominante "para isso, ela toma as si todas as crianças de todas as classes sociais e thes inculca durante anos a fio de audiência obrigatória "saberes práticos" envolvidos na ideologia dominante" (SAVIANI, 2012 p. 22).

\subsection{PL NO MUNICÍPIO DE CRICIÚMA}

Concordantemente com as teses do MESP a níveis nacionais, o vereador Daniel Costa de Freitas filiado na época ao PP (Partido Progressista) e atualmente filiado ao Partido Social Liberal $(\mathrm{PSL})^{7}$ é o porta voz do movimento no município de Criciúma.

De sua autoria o PL № 130/2017 institui, no âmbito do sistema municipal de ensino, o "Programa Escola sem Partido". Este nada mais é que uma cópia do PL 867/2015 proposto em âmbito nacional. O PL 130/2017 teve entrada na Câmara de Vereadores no dia 29/08/2017 este mesmo passou por leitura em plenário, e conforme a lei foi encaminhada para assessoria jurídica, que e por sua vez encaminhou em 11/09/2017 à Comissão de Constituição, Justiça e Redação da Câmara de Vereadores o seu parecer quanto a legalidade e constitucionalidade do projeto.

No parecer № 330/20178 a assessoria jurídica julgou ilegal e inconstitucional o projeto. Abaixo o trecho onde a assessoria deixa clara a inconstitucionalidade do projeto por ferir a Constituição Federal e as leis de diretrizes de bases da educação;

Contudo, como se vê, o projeto de lei em questão, institui, no âmbito do sistema municipal de ensino, o "Programa Escola sem Partido", o que viola o padrão constitucional vigente, por tratar de matéria cuja

\footnotetext{
${ }^{7}$ Este partido tem como principais ideologias o conservadorismo e o liberalismo econômico (neoliberalismo) deste mesmo partido também é filiado o já supracitado deputado federal e pré-candidato à presidência Jair Bolsonaro (PSL/RJ).

${ }^{8}$ CRICIÚMA. Parecer jurídico No 330/2017. Projeto de lei - PL n. ${ }^{\circ} 130 / 2017$. Criciúma/SC. Acesso em 24 de maio de 2018. 18p. disponível em > https://www.camaracriciuma.sc.gov.br/documento/projeto-pl-no-1302017-27898
} 
competência é privativa da União, ou seja, legislar sobre diretrizes e bases da educação nacional. Embora o projeto regulamente matéria de interesse local no âmbito do sistema municipal de ensino, não pode o Sr. Vereador legislar sobre esse assunto em afronta a dispositivos de Lei de Diretrizes e Bases da Educação que compete à União estabelecer normas gerais sobre o tema. (parecer jurídico $330 / 2017)$

O projeto em âmbito municipal afronta como visto no trecho acima a competência da união em legislar. Dessa forma vai contra o Art. 22. "Compete privativamente à União legislar sobre: (...) XXIV - diretrizes e bases da educação nacional" (CF,1988) também se afronta com a Art. 24. "Compete à União, aos Estados e ao Distrito Federal legislar concorrentemente sobre: (...) IX - educação, cultura, ensino, desporto, ciência, tecnologia, pesquisa, desenvolvimento e inovação" (CF, 1988).

Neste maneira cabe a união e ao estado de forma concorrente legislar sobre a educação e não ao município, mesmo que seja de interesse do mesmo.

A Constituição explicita, ainda, como se dá a distribuição da competência legislativa concorrente, ao dispor:

Art. 24. [...]

$\S 11^{\circ}$ No âmbito da legislação concorrente, a competência da União limitar-se-á a estabelecer normas gerais.

$\S 2^{\circ}$ A competência da União para legislar sobre normas gerais não exclui a competência suplementar dos Estados.

$\S 3^{\circ}$ Inexistindo lei federal sobre normas gerais, os Estados exercerão a competência legislativa plena, para atender a suas peculiaridades.

$4^{\circ}$ A superveniência de lei federal sobre normas gerais suspende a eficácia da lei estadual, no que Ihe for contrário. Sem grifo no original. (parecer jurídico 330/2017)

O parecer jurídico deixa claro a ilegalidade e inconstitucionalidade do PL 130/2017 em suas dezoito páginas. Mesmo com esta declaração o PL seguiu em frente na Câmara de Vereadores, ignorando o parecer a comissão de constituição, justiça e redação aprovou o projeto dando a ele legalidade e passando o $\mathrm{PL}$ a frente, a próxima comissão que julgaria $\circ \mathrm{PL}$ seria a Comissão de Educação, Cultura, Esporte, Turismo, Saúde, Meio Ambiente, Assistência Social e Direitos Humanos e posteriormente a Comissão de Fiscalização, Controle e Orçamentos, estas duas seguindo a lógica aprovaram o PL sem problemas.

Estas comissões são formadas pelos próprios vereadores, o que é um grande problema, por se exigir destes competência para julgar algo que não é 
de sua área de conhecimento. Façamos uma crítica ao próprio propositor do PL o vereador Daniel Freitas que em sua biografia de profissão identifica-se como "empresário". A falta de competência dessas pessoas para julgar assuntos que não diz respeito é gigante. Apesar da comunidade escolar municipal, o Sindicato dos Trabalhadores em Educação (SINTE/SC) e a comunidade acadêmica da Universidade do Extremo Sul Catarinense ${ }^{9}$ (Professores e alunos) se posicionarem contra a PL e irem a Câmara de Vereadores nas seções e explicitarem sua preocupação com a educação municipal, argumentarem contra a legalidade do projeto, estes foram ignorados pelos vereadores.

Sob protestos a favor (Movimento vem pra rua) e contra (movimento escola democrática, alunos, professores e comunidade em geral) o PL $130 / 2017$ foi aprovado no dia 11/12/2017 por 14 votos favoráveis e 02 contrários.

Torna-se então no dia 04/01/2018 lei № 7.159/2018 publicada no diário oficial do município ${ }^{10}$ e consequentemente sancionada pelo prefeito Clésio Salvaro (PSDB/SC).

Logo após a aprovação do PL, o ministério público federal por meio do sala de atendimento ao cidadão $(S A C)^{11}$ deu entrada com o parecer de inconstitucionalidade a procuradoria da república no município de Criciúma, que repassou o despacho apresentado a procuradoria geral da república (PGR).

O despacho alega que a lei apresenta vícios de constitucionalidade, além de violar normas da Lei de Diretrizes e Bases da Educação (Lei 9.394/96). Este documento alega tudo o que já havia sido representado pela assessoria jurídica aos vereadores. A inconstitucionalidade e ilegalidade do projeto é deixado claro nos dois documentos. O despacho até a momento aguarda leitura e julgamento do ministro Luís Roberto Barroso do Supremo Tribunal Federal (STF) que já deu indícios de ilegalidade a outros projetos espelhados no PL 867/2015, o ministro já vetou como mencionado

\footnotetext{
${ }^{9}$ Este encabeçado pelo movimento escola democrática.

10 Pode ser acessado neste link http://www.criciuma.sc.gov.br/pmc/webroot/upload/151510198604-012018.pdf

${ }^{11}$ Pode ser acessado neste link> http://www.mpf.mp.br/sc/sala-de-imprensa/docs/despacho-escola-sem-partido
} 

programa Escola Livre no estado.

O julgamento do ministro Barroso deixa claro, em diversos pontos as mazelas do projeto e o ataque direto a educação emancipatória, ao pensamento crítico, ao pluralismo de ideias e aos professores.

\begin{abstract}
A Constituição assegura, portanto, uma educação emancipadora, que habilite a pessoa para os mais diversos âmbitos da vida, como ser humano, como cidadão, como profissional. Com tal propósito, define as diretrizes que devem ser observadas pelo ensino, a fim de que tal objetivo seja alcançado, dentre elas a mencionada liberdade de aprender e de ensinar; o pluralismo de ideias e de concepções pedagógicas; a valorização dos profissionais da educação escolar. (trecho retirado so julgamento do ministro Luis Roberto Barroso, 2017'2)
\end{abstract}

Concordantemente como diversos teóricos da educação, como Paulo Freire, Bell Hokes, Theodor Adorno etc. O ministro entende a educação como forma de emancipação e libertação de uma sociedade cada vez mais desigual.

$\mathrm{O}$ projeto no âmbito municipal como já comentado aguarda analise e julgamento no STF, já o projeto de lei que tramitava no senado foi retirado pelo seu proponente o senador Magno Malta (PR/ES) a pedido do MESP e seu criador, Miguel Nagbi no dia 20/11/2017. O projeto não tinha força no senado, e por tanto sofreria uma derrota nas votações, já o mesmo PL que está em trâmite na câmara de deputados está com mais força, e leva a maioria dos votos. Situação preocupante, pois, estes votos são de deputados com ligações religiosas, principalmente evangélicos, membros da Renovação Carismática, estes fundamentalistas religiosos "se aliam a diferentes forças conservadoras no Congresso, como os latifundiários e os defensores dos armamentos, numa ação conjunta que fortalece a todos." (MIGUEL, 2016, p.593).

\title{
3. O PROJETO E O ENSINO DE/DA GEOGRAFIA
}

As disciplinas escolares mais visadas pelo MESP são história, geografia, filosofia e sociologia, estas por tratarem diretamente e indiretamente de

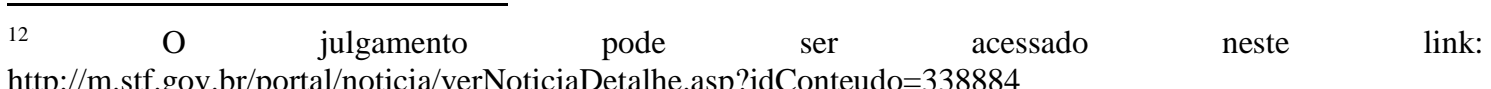


questões políticas da sociedade, de gênero, de desigualdade sociais, de racismo, e outras formas de preconceito existentes em nossa sociedade. ${ }^{13}$

O que nos interessa aqui é analisar como esse projeto vai interferir nos ensinos de geografia na educação básica de ensino. A geografia, vem ganhando outro caráter com a evolução do pensamento geográfico até os dias atuais, em especial no que se diz ao seu ensino mais humano, nas relações sociais (lutas sociais) e nas relações de produção. Especialmente após os anos 1970/1980 com a chamada geografia crítica/radical, essa nasce após o enfraquecimento da chamada geografia quantitativa (ou nova geografia).

A geografia crítica sucede a corrente do pensamento geográfico denominada nova geografia ou geografia quantitativa, que surgiu durante a Guerra Fria, em meados do século XX, na Inglaterra, Estados Unidos e Suécia - corrente que, pautada em métodos quantitativos, encobria o compromisso ideológico de justificar a expansão capitalista sem exprimir a essência da realidade social (MOURA et al $2008 \mathrm{~s} / \mathrm{p}$ )

Esta nova geografia, justificava em seus meios a expansão capitalista, sem se opor, e sem um olhar para os países do Sul, em especial os do continente Africano e América Latina, na sua constante exploração e neocolonização. É fato que no sistema capitalista para que existam países desenvolvidos é preciso haver os que supram os anseios de consumo destes. Nesse sentido essa corrente de pensamento apenas reforça as relações de dominação vigentes. Por tanto como afirma Moura et al (2008):

É nesse contexto de dominação pelo uso ideologizado da informação, assim como de agravamento das tensões sociais nos países centrais e movimentos por independência nos países subdesenvolvidos, que a geografia crítica emerge como uma corrente que se opõe à quantitativa. (MOURA et al $2008 \mathrm{~s} / \mathrm{p}$ )

Esta oposição da geografia crítica nasce, e se difunde entre os anos 1970/1980 e 2000. Tendo como seus principais expoentes e renovadores os professores Milton Santos, Ariovaldo Umbelino de Oliveira, mais na área acadêmica, José Willian Vesentine e Vania Vlach destacam-se por suas obras e livros didáticos para o ensino fundamental. As obras acadêmicas em torno desta renovação apontando as críticas ao sistema globalizado, ao imperialismo

\footnotetext{
${ }^{13}$ Também são visadas as disciplinas de ciências, biologia e física. A sociedade brasileira de física lançou nota no seu site oficial posicionando-se contrários ao MESP. "Escola Sem Partido ameaça ensino de ciência nas escolas" http://www.sbfisica.org.br/v1/index.php?option=com_content\&view=article\&id=940:2017-08-31-1258-29\&catid=152: acontece-na-sbf \&Itemid $=270$
} 
e as novas ordens mundiais tornaram-se objeto de estudo por muitos geógrafos, principalmente dentro da universidade, mas pouco comparecida no ensino fundamental.

Mesmo com diversas obras acadêmicas e uma nova leitura da sociedade, esta geográfica crítica não conseguiu romper os laços de dominação vigentes, ou seja, "apesar de possuir uma leitura crítica da realidade, a geografia ativa não rompe, em termos metodológicos, com a análise tradicional, pois se mantém descritiva e empirista." (Moura, $2008 \mathrm{~s} / \mathrm{p}$ ).

Este rompimento se mostra como já dito, de maneira mais vigente dentro da academia (universidades, faculdades) mas não nas escolas, onde deveriam se dar de forma mais reveladora diante os problemas sociais (OLIVEIRA, 1991). Tanto Oliveira (1991) quanto Lacoste (2001) trabalham a ideia da dualidade da geografia, isto é, existe uma geografia feita na academia e outra nas escolas denominada por Lacoste (1991) de geografia dos professores.

A geografia dos professores encontra-se dentro das escolas até os dias atuais, pois de certa forma a renovação da geografia e sua capacidade de criticar as relações sociais a ponto de transforma-las não chega a todos professores (alguns não aceitam, outros não se renovam). Esta geografia feita em sala de aula, a dos professores é "um discurso ideológico no qual uma das funções inconscientes, é a de mascarar a importância estratégica dos raciocínios centrados no espaço" (LACOSTE, 1991 p. 31).

A exemplo de Brasil temos a geografia ensinada durante o século XX na qual tinha por objetivo "Difundir uma ideologia patriótica e nacionalista: eis o escopo fundamental da geografia escolar. Inculcar a ideia de que estado-nação é natural eterna; apagar da memória coletiva as formas anteriores de organização espacial das sociedades" (VESENTINE, 1991 p.32) ou ainda nas palavras de Oliveira (1991 p.135)

\begin{abstract}
A sua história (da geografia) tem sido um a valorização dos grandes projetos governamentais, de modo a ir construindo na mente das crianças conceitos de estado, nação, governo, território, país, como realidades definidas do ponto de vista do estado capitalista.
\end{abstract}

Para esses autores este foi o papel da geografia durante o século XX 0 de exaltar o estado, e de certa forma continua sendo até hoje, um pouco diferente, mas com a mesma finalidade, ainda ensinamos a organização do 

estes assuntos tratados em sala de aula, pois ainda de certa forma não condicionamos o ensino com a realidade do aluno. "O que ocorre na realidade é que os professores (todos) obviamente os de geografia também, estão envolvidos em um processo dialético de dominação" (OLIVEIRA 1991 p.28). E apenas legitimamos o que Lacoste (2001) chama de disciplina "inútil":

Por causa disso a minoria no poder tem consciência de sua importância (a da geografia), é a única a utilizá-las em função dos seus próprios interesses e este monopólio do saber é bem mais eficaz porque a maioria não dá nenhuma atenção a uma disciplina que lhe parece tão perfeitamente "inútil” (LACOSTE, 2001 p. 31)

A função então da geografia crítica é de não se calar perante as injustiças sociais evidentes, e demostrar que a geografia serve mais que apenas para fazer a guerra, estudar o espaço ou decorar o nome dos afluentes do Rio Amazonas. Esta novíssima geografia dos novos professores deve fazer com que estes educandos façam parte de fato do processo de ensino/aprendizagem, não os tratando mais como simples ouvintes ou caixas eletrônicos ${ }^{14}$.

O professor deve antes de tudo, trabalhar na perspectiva que ele é apenas um facilitador do processo, um "norte" (para usar um termo geográfico), e ir rumo a uma geografia menos mnemônica, decorativa, enciclopedista (BRABANT, 1991).

E se o professor não raciocinar em termos de "ensinar algo" e sim de "contribuir para o desenvolvimento de potencialidades" do aluno, ele verá que o conhecimento também é poder, serve para dominar ou combater a dominação, e que o educando pode tornar-se coautor do saber (som os estudos do meio participativos, debates frequentes, textos e conteúdo adequados a realidade social existencial dos alunos. (VESENTINE, 1991 p.37)

Combater a dominação, de um estado autoritário, de um sistema capitalista de produção onde a cada dia se produz mais desigualdades entre os homens, eis aí o papel da escola, de todas as disciplinas, em especial aquelas que trabalham diretamente com a sociedade e suas relações (história,

\footnotetext{
14 Usando aqui a concepção bancaria de Paulo Freire "Em lugar de comunicar-se, o educador faz "comunicados" e depósitos que os educandos, meras incidências, recebem pacientemente, memorizam e repetem. Eis aí a concepção "bancária" da educação, em que a única margem de ação que se oferece aos educandos é a de receberem os depósitos, guardá-los e arquivá-los”. (FREIRE, 1994 p. 33)
} 
geografia, sociologia, filosofia) pois como diria Francis Bacon "conhecimento é poder".

Fazer do educando coautor desta transformação é apenas seguir o que Paulo Freire tanto pregava em suas obras, transformar os educandos por meio de uma pedagogia da autonomia, tornar seres autônomos sem amarras sociais. Concordantemente Vesentine (1991) conclui:

\begin{abstract}
Em outros temos, o conhecimento a ser alcançado no ensino, na perspectiva de uma geografia crítica, não se localiza no professor ou na ciência a ser "ensinada ou vulgarizada, e sim no real, no meio onde o aluno e professor estão situados e é fruto da práxis coletivas dos grupos sociais. Integrar o educando no meio significa deixa-lo descobrir que pode tornar-se sujeito da história VESENTINE, 1991 p.37).
\end{abstract}

Tornar o sujeito autônomo, ou torna-lo sujeito da história eis aí algo perigoso para o sistema, para os dominantes e para aqueles que ainda acreditam que o capitalismo é uma saída para as desigualdades. Neste sentido o PL 867/2015 em âmbito nacional e a já aprovada lei № 7.159/2018 no município de Criciúma vem contra esta prática libertária da escola e das disciplinas de ciências humanas, onde ser-se-ia a discussão em sala de aula, pondo o professor em constante vigilância e criando um ódio a classe docente (PENNA, 2017).

Em suas entre linhas podemos por como ameaça a criticidade em sala de aula o cerceamento a discussão, principalmente da parte política e nas relações humanas.

O PROGRAMA IMPEDE O PROFESSOR DE FALAR DE POLÍTICA? Não. Seria impossível ensinar História ou Geografia, por exemplo, sem falar de política. Ao falar de política, porém, o professor deve ter o cuidado de apresentar aos alunos o "outro lado" da moeda, sem omitir, exagerar ou distorcer informações, com o objetivo de obter a adesão dos alunos a determinada corrente ideológica, política ou partidária. ${ }^{15}$

O que se define como doutrinação ideológica/partidária não explicitamente nos artigos, mas nos discursos de seus defensores, são as ideologias ditas de esquerda estes discursos abertamente conservadores, e retrógados apresentam as ideias de esquerda como dominantes dentro das escolas e das universidades, e acusam os professores de tentarem de alguma

15 Retirado do site do MESP> https://www.programaescolasempartido.org/faq 
forma entubar esta ideologia nas crianças e torná-los militantes. Além de criminalizam a prática docente, e a liberdade de expressão.

IV - Ao tratar de questões políticas, socioculturais e econômicas, o professor apresentará aos alunos, de forma justa - isto é, com a mesma profundidade e seriedade -, as principais versões, teorias, opiniões e perspectivas concorrentes a respeito da matéria. (deveres do professor)

No discurso difundido pelo criador do MESP Miguel Nagbi, a busca de neutralidade por parte do professor é algo do seu desejo, e para isso ele justifica rebaixando a profissão ao mero exercício burocrático de transmissão de conhecimento (PENNA, 2017). O PL também prevê a fixação de um cartaz em sala de aula, sala dos professores e locais visíveis na escola medindo 70 centímetros de altura por 50 centímetros, contendo os deveres do professor (ou os direitos dos alunos), o medo que o professor terá de lecionar qualquer tema que seja "delicado" aos olhos do MESP.

Isso o impedirá de dar o seu potencial em sala de aula, deixando-o com receio a todo tempo, a neutralidade em sala de aula é impossível e demostrada teoricamente por diversos autores. Paulo Freire já nos dizia: "Não existe imparcialidade. Todos são orientados por uma base ideológica. A questão é: sua base ideológica é inclusiva ou excludente?"

Nesse sentido para os apoiadores do MESP ter uma ideologia inclusiva implica em o professor ser um militante de esquerda, ou seja, lutar contra as desigualdades sociais sejam elas quais forem, o professor torna-se um militante/doutrinador, e por mais que nos sou engraçado, esta é a realidade, e virou lei no município de Criciúma e em outros do Brasil, e esta prestes a se tornar lei federal e ser incluído nas diretrizes de bases da educação. 0 cerceamento da discussão, o medo de lecionar, tornam o professor um mero burocrata repassando os conteúdos e retirando a criticidade de dentro da sala de aula.

Mas para que isso não ocorra, diversos movimentos contrários lutam em todos os estados brasileiros, em Criciúma o movimento Escola Democrática apresenta-se como principal atuante, encabeçado por professores universitários, da educação básica e alunos de licenciatura. Diversas obras e artigos contra o "escola sem partido" já foram publicados demostrando toda sua 
incapacidade constitucional, e suas afrontas as teorias educacionais, mas ainda seus mentores insistem em tornar lei. Vemos nestes momentos que uma educação crítica, emancipatória e democrática de fato é uma ameaça ao sistema.

Neste sentido a disciplina de geografia será uma das mais visadas, e vigiadas pelos defensores do movimento. Os professores estarão em constante vigilância, e irão lecionar com medo, mas não com medo de processos, mas com medo de não conseguirem por meio da educação tornar o aluno sujeito de sua própria geografia.

\section{CONSIDERAÇÕES FINAIS}

Este projeto além de inconstitucional e criminoso, busca legitimar cada vez mais este sistema machista, homofóbico, racista e opressor das minorias sociais, já não se basta que os governos não tenham medidas públicas suficientes para lidar com estes problemas, uma lei mal estruturada e com vícios de constitucionalidade está se difundindo pelo país e sendo aprovada em diversos municípios e ganhando apoio de grupos conservadores que agem dentro do congresso nacional.

Este PL foi criado e difundido por pessoas que não são da área da educação e que nunca botaram os pés em uma sala de aula, e não convivem com a realidade das escolas públicas brasileiras, além de responsabilizar os professores por todas as mazelas da educação e "defendem abertamente a criminalização da sua prática. Sem a valorização dos professores, nenhum projeto educacional pode prosperar, seja ele voltado para a educação democrática ou não" (PENNA, 2017 p. 260).

Esta desvalorização do professor, não se dá apenas na questão salarial ou nas condições de trabalho, mas no rebaixamento da profissão de educador para um burocrata a serviço do estado, e de pôr o professor em constante vigilância, podendo ser processado a qualquer momento. Professores de todo Brasil e organizações nacionais e internacionais se posicionam contra este projeto, mesmo assim o PL segue em frente, e não sendo diferente no município de Criciúma gera a angustia dos educadores e a preocupação com o que está prestes a vir no próximo ano (a lei entra em vigor no ano de 2019) se 
a lei não for vetada no STF. Mas, perseveramos e como afirma a professore Gaudêncio Frigoto (2016, p.13):

\begin{abstract}
Haja cadeias, pois os docentes do Brasil, em suas organizações científicas, culturais, sindicais e por franjas de partidos políticos que atuam nos parlamentos proclamam: não somos idiotas, esta mordaça não vingará, mesmo que a insanidade ou os que não percebem 0 alarme da esfinge a constituam em lei. (FRIGOTTO, 2016 p.3)
\end{abstract}

A lei № 7.159/2018 que estabelece o programa "escola sem partido" no município de Criciúma encontrasse em tramite no ministério público e procuradoria geral da república, para posteriormente se enviado a análise no STF. Até lá resistimos e lutemos para uma educação libertária, e por um mundo menos desigual, onde todos teremos direito à pão, paz e terra.

\title{
5. REFERÊNCIAS BIBLIOGRÁFICAS
}

ALENCAR, Diego Pinheiro. EDUCAÇÃO E NEOLIBERALISMO: o caso do projeto escola sem partido. Revista Brasileira de Educação em Geografia, Campinas, v. 714, p.127-140, jul. 2017. Semestral. Disponível em: <www.revistaedugeo.com.br > Capa > v. 7, n. 14 (2017) > Alencar>. Acesso em: 10 maio 2018.

ALTHUSSER, Louis. Aparelhos Ideológicos de Estado. 3ª edição. Rio de Janeiro: Edições Graal, 1987.

BRASIL. Lei n. 9.394, de 20 dez. 1996 (Lei de Diretrizes e Bases da Educação

- LDB). Estabelece as diretrizes e bases da educação nacional. Disponível em: <http://www.prolei.inep.gov.br>. Acesso em: 18 maio. 2018.

\section{BRASIL. Constituição (1988) Constituição da República Federativa do Brasil. \\ 40 ed. São Paulo: Saraiva, 2007.}

BAUMAN, Zygmunt (2001). Globalização: as consequências humanas. Rio de Janeiro: Jorge Zahar Ed., 1999

BRABANT, Jean-Michel. Crise da geografia, crise da escola. In: OLIVEIRA, Ariovaldo Umberlino de (Org.). Para onde vai o ensino de geografia? São Paulo: Contexto, 1991. p. 15-23. (Repensando o ensino).

FREIRE, Paulo. Ação cultural para a liberdade. Rio de Janeiro: Paz e Terra, 1984.

FRIGOTTO, Gaudêncio. Org. Escola 'sem' partido: esfinge que ameaça a educação e a sociedade brasileira. Rio de Janeiro: LPP, Uerj, 2017. 144p. 
FRIGOTTO, Gaudêncio. "ESCOLA SEM PARTIDO": IMPOSIÇÃO DA MORDAÇA AOS EDUCADORES. E-mosaicos, [s.I.], v. 5, n. 9, p.11-13, 19 jul. 2016. Universidade de Estado do Rio de Janeiro. http://dx.doi.org/10.12957/emosaicos.2016.24722. Disponível em: <http://www.e-

publicacoes.uerj.br/index.php/e-mosaicos/article/view/24722/17673>. Acesso em: 13 jun. 2018.

HOOKS, Bell. Ensinando a transgredir: a educação como prática de liberdade. São Paulo: Martins Fontes, 2013. 144 p. Tradução de Marcelo Brandão Cipola.

\section{LACOSTE, Yves. A geografia - isso serve, em primeiro lugar para fazer} guerra. Tradução Maria Cecília França - Campinas, SP: Papirus, 2001.

MIGUEL, Luis Felipe. Da "doutrinação marxista" à: Escola Sem Partido (nonpartisan school) and gag laws in Brazilian congress. Revista Direito e Práxis, [s.l.], v. 7, n. 15, p.590-620, 14 set. 2016. Universidade de Estado do Rio de Janeiro. http://dx.doi.org/10.12957/dep.2016.25163. Disponível em:

<http://www.e-publicacoes.uerj.br/index.php/revistaceaju/article/view/25163>. Acesso em: 10 maio 2018.

MOURA, Fernanda Pereira de. "Escola Sem Partido": relações entre estado, educação e religião e os impactos no ensino de história. 2016. $188 \mathrm{f}$.

Dissertação (Mestrado) - Curso de Mestrado Profissional do Programa de Pósgraduação em Ensino de História, Centro de Filosofia e Ciências Humanas Instituto de História, Universidade Federal do Rio de Janeiro, Rio de Janeiro, 2016. Disponível em:

$<$ https://educapes.capes.gov.br/bitstream/capes/174584/2/Dissertação Fernanda Pereira de Moura.pdf>. Acesso em: 10 maio 2016.

MOURA, Rosa; OLIVEIRA, Deuseles de; LISBOA, Helena dos Santos; FONTOURA, Leandro Martins, GERALDI, Juliano. Geografia Crítica: legado histórico ou abordagem recorrente? Biblio 3W. Revista Bibliográfica de Geografía y Ciencias Sociales, Universidad de Barcelona, Vol. XIII, no 786, 5 de junio de 2008. <http://www.ub.es/geocrit/b3w-786.htm>. [ISSN 1138-9796].

OLIVEIRA, Ariovaldo Umberlino de. Educação e ensino de geografia na realidade brasileira. In: OLIVEIRA, Ariovaldo Umberlino de. Para onde vai o ensino de geografia. São Paulo: Contexto, 1991. p. 30-38. (Repensando o ensino).

OLIVEIRA, Ariovaldo Umberlino de. Situação e tendências da geografia. In: OLIVEIRA, Ariovaldo Umberlino de. Para onde vai o ensino de geografia. São Paulo: Contexto, 1991. p. 30-38. (Repensando o ensino).

PENNA, Fernando de Araújo. A "Escola sem Partido" como ameaça à Educação Democrática: fabricando o ódio aos professores e destruindo o potencial educacional da escola. In: MACHADO, André Roberto de A.; TOLEDO, Maria Rita de Almeida (Org.). Golpes na História e na Escola: o 


\section{CRIAR EDUCAÇÃO}

Revista do Programa de Pós-Graduação em Educação - UNESC

Brasil e a América Latina nos séculos XX e XXI. São Paulo: Cortez, 2017. p. 247-260.

ROCHA, Valéria da; PÁDUA, L. A Geografia: isso serve, em primeiro lugar, para o quê? In: Anais... 12 ${ }^{\circ}$ EGAL - Encontro de Geógrafos da América Latina, 2009, Montevideo. Caminando en una América Latina en transformación, 2009.

SAVIANI, D. Escola e democracia: teorias da educação, curvatura da vara, onze

teses sobre educação e política. 32 ed. São Paulo: Cortez/Autores

Associados,

1999.

SAVIANI, Demerval. Escola e democracia. 42. ed. Campinas: Autores Associados, 2012. $92 \mathrm{p}$.

VESENTINE, José Willian. Geografia crítica e ensino. In: OLIVEIRA, Ariovaldo Umberlino de. Para onde vai o ensino de geografia. São Paulo: Contexto, 1991. p. 30-38. (Repensando o ensino). 